\section{Environmental Configuration and Innovation: Different Impacts in the Measurement of the Innovative Process in Brazil and in its States}

\author{
Gutemberg Ribeiro ${ }^{1, \dagger}$ \\ ${ }^{1}$ Universidade Federal do Paraná, Curitiba, PR, Brazil \\ Ana Paula Mussi Szabo Cherobim 2,Q \\ ${ }^{2}$ Universidade Federal do Paraná, Curitiba, PR, Brazil
}

\begin{abstract}
This article aims to demonstrate that environmental variables can assume differentiated values over a given period and associate themselves to form configurations of different contexts. Knowing the possible configurations of the organizational environment, we are able to identify which indicators are most appropriate to measure innovation, thus meeting the basic condition to manage innovation: to measure accurately the phenomenon under analysis. Thus, with the empirical data analysis from Brazil and the states of São Paulo, Paraná and Sergipe, we are able to highlight and characterize the different environmental configurations and their reflexes for the innovation measurement process. It should be emphasized that the environmental configuration appears as a relevant factor that must be considered in the process of measurement and management of innovation aiming at competitiveness.
\end{abstract}

Keywords: Environmental configuration. Innovation. Competitiveness. Indicators. Environmental variables.

\section{INTRODUCTION}

Various studies seek to characterize which factors have the greatest impact on the treatment of innovation. And among those found in the literature, the environment stands out. However, despite numerous discussions about the influence of the environment on innovation (DAMANPOUR, 1996; TIDD, 2001; MANUAL de OSLO, 2005; ZHANG; MAJID; FOO, 2011; TSUJA; MARIÑO, 2013), very little about this influence has been effectively portrayed in scientific studies (FAGERBERG, 2004; RIBEIRO; CHEROBIM, 2017a).

The restrictive and deterministic character of the environment is evidenced from the conception of the contingency theory, which has a strong influence on organizations and their strategies for achieving survival. However, we observe in the literature that the influence of the environmental context is generally treated in a generic way, without characterizing its specificities. The various characteristics attributed to the environment that make it difficult to address are commonly observed. These include complexity, dynamics, uncertainty, unpredictability and volatility (RIBEIRO; CHEROBIM, 2017a). Although these adjectives are very pertinent, we note that they are comprehensive, generalist and linked to any environment.
Corresponding author:

† Universidade Federal do Paraná, Curitiba, PR, Brazil.

E-mail: gutemberg26@uol.com.br

${ }^{\Omega}$ Universidade Federal do Paraná, Curitiba, PR, Brazil.

E-mail: cherobimanapaula@gmail.com

Received: $05 / 23 / 2017$

Revised: 02/16/2018

Accepted: 03/15/2018

Published Online: 09/26/2018

DOI: http://dx.doi.org/10.15728/bbr.2018.15.6.5 
Regardless of the type of environment, organizations are faced with the challenge of knowing and understanding environmental contingencies so that they can create and leverage innovation (LI; ATUAHENE-GIMA, 2001; TIDD, 2001), understood as the successful application and exploitation of an idea, even if the novelty is only at the local level (MANUAL DE OSLO, 2005). However, it is difficult to have an effective conception of the environment without knowing its parts, characterized by environmental variables and configurations. Thus, in this article we seek to answer the following research question: do environmental variables assume different values over time and conform differently, providing different environmental configurations?

By characterizing the dynamicity of variables and the possibilities of environmental configurations, understanding and managing the interaction of the environment and innovation becomes less complex. This paper aims to demonstrate that environmental variables assume differentiated values over a given period and correlate in a way to configure different contexts. Knowing the possible configurations of the environment is important in order to exploit innovation in competitive organizational strategy.

Thus, we justify this study by seeking to present empirical elements to reduce some of the gaps with practical application results, these include: 1) the absence of studies effectively considering the relationship of the environment to the innovation process; and 2) the lack of evidence that environmental variables or factors can correlate in order to shape certain configurations that impact innovation and require more adequate indicators for their measurement. We use data from environmental variables related to Brazil and the states of São Paulo, Paraná and Sergipe, which have differentiated degrees of innovation.

\section{The Conception of Organizational Environment}

In an objective way, environment is all that we find outside a system, which is conceived as a set of interacting and interdependent parts that relate to a common goal (BERTALANFFY, 1968). The environment concerns the various social and physical factors that influence the organizational decision-making process and that are beyond the limits of the organization (McGEE; SAWYERR, 2003).

Tsuja and Mariño (2013) define environment as a set of external factors that interact causing reflections in the organization. These factors are characterized by uncertainty and complexity. For these authors uncertain environment is where frequent changes occur in the external variables that impact the organization. However, the complex environment is characterized by covering a large number of external variables that influence the organization.

Another characteristic of the environment, according to Duncan (1972), is the dynamicity, described as the speed of changes in environmental variables in a given period of time. As environmental conditions change rapidly and constantly, another typical feature of the environment emerges: volatility. Therefore, uncertainty, complexity, dynamicity and volatility are the main characteristics of the organizational environment.

The environment impacts the organizational dynamics and strategy (DAMANPOUR, 1996; TIDD, 2001), and understanding it with its attributes is fundamental for the organization to remain in the market (MOYSÉS FILHO et al., 2010). Therefore, their strategies must be thought and conducted considering the necessity of the homeostasis, so that the organizational survival is guaranteed. And one of the strategies in this sense is the environmental mapping (HAMBRICK, 1982; ZHANG; MAJID; FOO, 2011), which provides the information necessary for the actions of organizations.

In addition to environmental mapping, we need to know and understand the dimensions of the environment: 1) microenvironment: task or domain environment; and 2) macroenvironment: remote environment. The first type is significant and has a direct impact on the organization's tasks and results and includes consumers, suppliers, competitors and other 
BBR

15,6

stakeholders. The other type, which is also important, has an indirect and long-term impact, including economic, educational, social, cultural, technological and legal variables (MANUAL DE OSLO, 2005; MOYSÉS FILHO et al., 2010; MYBURGH, 2004).

\section{Characterization Of InNovation}

Despite the various models of innovation, its concept has always revolved around the application of knowledge that adds value to something. For Schumpeter (1939) innovation is a function based on creative thinking and action, where products and consumption habits are replaced by new ones; innovation is everything that differentiates and gives value to a business. With the Oslo Manual (2005), the concept of innovation was expanded, characterized as the implementation of a new or significantly improved product, a process, a new marketing method, or the implementation of a new organizational method in business practices, in the workplace organization or in external relations.

It is true that the creative action of innovation gives the organization the ability to produce new products and services. In meeting the needs of the market, innovation expands organizational competitiveness. This is the reason for the increase in the number of studies on innovation and its impact on productivity and competitiveness (SANTOS; VASCONCELOS; DE LUCA, 2013).

To better understand innovation, it is important to situate it in the context where it occurs and its scope. In this sense, innovation presents differentiated characteristics if analyzed at company, regional or national level (MANKIW, 2003). This segmentation has a consistent impact on internal and external factors (environmental context) related to the creation, application and diffusion of innovation, such as human resources (CASSIOLATO; LASTRES, 2000), markets (BARNEY, 1991; PORTER, 2008), institutional conditions (SCHUMPETER, 1939), political and economic aspects (SILVA; DA SILVA; MOTTA, 2012).

The literature presents several types of innovation (RIBEIRO; CHEROBIM, 2017b), but the radical and incremental types proposed by Schumpeter (1939), still predominate on a consolidated basis. Regardless of type, it is paramount to identify secure ways of measuring innovation. Although there is no universal tool for measuring innovation and competitiveness (FREEMAN; SOETE, 2007), a positive way of reducing uncertainties as measurement goes through the understanding of how the environment influences them. In this aspect, the understanding of the behavior of the environmental variables and the way of conforming are presented as basilar for the management of innovation.

\section{Methodology}

We use the exploratory and descriptive research strategy in this study. To make them operational, we conduct a bibliographical research, through the EBSCO host platform database and the journal portal of the Coordination for the Improvement of Higher Education Personnel - CAPES, and bibliometric analyzes, using the public databases described in Table 1.

We conduct an empirical research through the secondary data analysis, characterizing as the analysis of data previously collected and tabulated by other sources (BHATTACHERJEE, 2012). We collected the data from the research's focus areas: Brazil, São Paulo, Paraná and Sergipe. The choice of the Brazil unit is due to the globalized approach of the variables. We selected the states based on their general characteristics of innovation, reflected in the competitiveness (EXAME, 2015), and the accessibility to the statistical data of the environmental variables.

Regarding the diversity of environmental variables (MANUAL DE OSLO, 2005; MOYSÉS FILHO et al., 2010; MYBURGH, 2004), these can be synthesized in: economic, 
Table 1. Public data sources

\begin{tabular}{|c|c|}
\hline Variables & Public database \\
\hline Economic & $\begin{array}{l}\text { Brazilian Institute of Geography and Statistics - } \\
\text { IBGE; Institute of Applied Economic Research } \\
\text { - IPEA; Central Bank of Brazil- BCB; Ministry of } \\
\text { Science, Technology, Innovation and Communica- } \\
\text { tions - MCTI; Ministry of Labor and Employment } \\
\text { - MTE; Economic Research Institute Foundation - } \\
\text { FIPE; Annual Report of Social Information - RAIS; } \\
\text { Worker Support Fund - FAT; National Confede- } \\
\text { ration of Industry - CNI; Federation of Industries } \\
\text { of the State of São Paulo - FIESP; Federation of } \\
\text { Industries of the State of Paraná - FIEP; Federation } \\
\text { of Industries of the State of Sergipe - FIES; and } \\
\text { Observatory of Sergipe. }\end{array}$ \\
\hline Educational & $\begin{array}{l}\text { Ministry of Education - MEC; National Develo- } \\
\text { pment Fund for Education - FNDE; The National } \\
\text { Institute of Educational Studies and Research Aní- } \\
\text { sio Teixeira - INEP; Coordination of Improvement } \\
\text { of Higher Education Personnel - CAPES; and Ob- } \\
\text { servatory of Sergipe. }\end{array}$ \\
\hline Social & $\begin{array}{l}\text { Brazilian Institute of Geography and Statistics - } \\
\text { IBGE; Ministry of Labor and Employment; Annual } \\
\text { Report of Social Information - RAIS; and Observa- } \\
\text { tory of Sergipe. }\end{array}$ \\
\hline
\end{tabular}

Source: The authors, 2016.

educational (including technological), social (encompassing cultural) and political (which encompass legal variables). In this research, we disregard the political variables for two reasons: 1) in the period of the study there was no alternation of the political group that commanded the country; and 2) the political variables do not show constancy of publication and reliability. Therefore, the environmental variables we considered are: economic, educational and social.

In the literature review we verify the absence of studies dealing with the relation between the environmental configuration and innovation and its indicators regarding the reflexes in the measurement process. In order to achieve the objective of this study, we establish two research hypotheses:

H1 - The environmental variables - economic, educational and social - can assume different values over a given period ranging from extremely positive positions to extremely negative positions and can correlate with each other; and

$\mathrm{H} 2$ - The correlation of the economic, educational and social variables, in their different forms (ranging from positive to negative), results in eight distinct environmental configurations.

We selected the indicators used to measure the value of each of the environmental variables from public databases. The database were built with annualized and available data. The result was comprised of 15 indicators available for each of the studied variables.

For the analysis of the H1 hypothesis, data were collected on the indicators referring to the variables in the Brazilian scope, allowing for a broad and generic analysis. For the $\mathrm{H} 2$ hypothesis, the data were collected deal with the indicators of the states selected for the research. The variables and indicators are summarized in Table 2.

Considering that this research deals with innovation and that the first research on the innovative process in Brazil occurred in the triennium 1998-2000, and the fact that this period 
BBR

15,6
Table 2. Indicators of the environmental variables used in the research

Environmental Variables

Indicators

Trade balance; Inflation; Number of patent filings; GDP; Gross value of industrial production; Consumption of cement; S\&T Expenditures; Public debt; Trademark Application; Average worker's

Economic variable income; Employed population; Average household income; Number of deposits of computer programs; Economically active population; Unemployment rate.

Enrollment rate; Number of higher education institutions; Number of years of school lag; Number of faculty with $\mathrm{PhD}$ (higher education); Number of faculty in higher education; Illiteracy rate, aged

10+; Graduates in doctor degree; Graduates in Educational Variable master's degree; Number of graduate scholarships; Number of students completing higher education; Rate of youth served at school; Functional illiteracy rate; Number of graduate scholarships with concept 5 ; Number of years of study - people aged 25+; Number of face-to-face courses.

Gini Coefficient; Coverage of garbage collection; Sanitation coverage; Absolute poverty; Total population; Number of available jobs; Number of physicians per inhabitant; Household rate with water supply; Household rate of precarious housing situation; Rate of urban lighting; Household rate with all essential services; Rate of urbanization; Rate of population participation; Theil Index - distribution inequality amongst individuals according to per capita income; employees formal contracted rate.

Source: The authors (2016), based on public sites.

was greatly influenced by the crisis of the Asian tigers (1997) an the Russian crisis (1998), with negative impact in Brazil, we excluded data from this period, as possible biases resulting from these crises could hardly be neutralized. Thus, we adjusted the period of data collection between 2001 and 2013. We established the upper limit based on the complete availability of data.

To facilitate the identification of the variable, we created a structure to comprise the data. Each variable received the designation of construct, represented by the letter "C", and named each indicator as variable, represented by the letter " $\mathrm{V}$ ". Thus, the economic variable termed as $\mathrm{C} 1$ and its first indicator of $\mathrm{V} 1$, so that the control code is $\mathrm{V} 1 \mathrm{C} 1$ (variable 1 of construct 1). For the educational variable we assigned the designation $\mathrm{C} 2$ and for the social $\mathrm{C} 3$. We adopted the same procedure for these variables regarding their indicators $(\mathrm{V} 1 \mathrm{C} 2$; V1C3). Due to the fact that there are several variables/indicators over the years, we used the technique known as "time series analysis" characterized by the set of observations over a period (STEVENSON, 1981).

In order to perform the calculations demanded in this research, we use the SPSS software (IBM/SPSS, 2012) and the GRETL (GRETL, 2013). Once the environmental variables were defined, with the respective measurement indicators, we identified some the database some missing values. We use an SPSS procedure that allows us to enter missing values. 
Because the database is presented as a panel, the literature points out that the main problems are related to normality (cross section) and whether or not the time series is stationary (stationarity). Regarding normality, we use secondary data only, they were already treated (normalized) at the time of the original research. In addition, the normality test is not recommended for small samples, which is the case of this research (2001-2013), depending on the loss of potency. Therefore, we calculated the Spearman correlation coefficient. As for stationarity, to avoid working with spurious correlations, we test the series using KPSS and stationarity by applying the first difference method, both in the GRETL application.

\section{Presentation And Discussion Of Results}

We verified that the use of correlation was responsible for standardizing the data under analysis, which is the process of transforming the standard score into Z-score (LEVINE et al., 2015). Therefore, the database was ready for the statistical calculations and analyzes resulting from the adaptation of the data contained in the preliminary spreadsheet migrated to the final spreadsheet, completing the missing value and carrying out the stationarity tests of the time series.

We used secondary data for each indicator per variable, expressed in Table 2, and we elaborated specific tables for each research site - Brazil, São Paulo, Paraná and Sergipe. Based on these tables, we ran the correlations through the SPSS application (IBM/SPSS, 2012), resulting in four data files with correlations for the sites surveyed considering the economic, educational and social environmental variables.

Because the series of the research is short, the literature recommends the use of Spearman's correlation coefficient, whose reading of the correlation hypothesis is related to the following conditions of comparison between null hypothesis (H0) and alternative hypothesis (H1): a) H0: There is no correlation between the pair of variables; the correlation between them is null; and b) $\mathrm{H} 1$ : There is correlation. Thus, if the p-value is lower than 0.05 , the $\mathrm{H} 0$ hypothesis must be rejected.

The correlation coefficient can range from -1 to +1 (minus one to one), indicating whether it is directly or indirectly related. It should also be pointed out that the SPSS application (IBM/SPSS, 2012) highlights the significant "correlations" (marked with an asterisk $(*))$ and the "very significant", (where two asterisks appear $(* *))$.

\subsection{Research Hypothesis TeST - H1}

In this test, the values of the indicators of the variables surveyed throughout the period and the correlations of the collected data with respect to Brazil. These correlations, with 15 economic variables (V1C1 to V15C1), 15 educational (V1C2 to V15C2) and 15 social (V1C3 to V15C3), set out in Tables 3, 4 and 5.

As for the different values over the studied period, we observe that variation occurs in the analyzed series, which is non-uniform and has no specific trend. This information can be seen in the indicators with the most changes over time in the economic, educational and social variables, constants of tables 6,7 and 8 , respectively.

Thus, the correlations between the indicators of each variable - economic, educational and social - demonstrate the specific conformation of the environment. For this purpose, we need to observe if there are correlations between the indicators of the same variable (intracorrelation) and between the indicators of different variables (intercorrelation).

Therefore, we analyzed the correlations of only the indicators of a given variable; then the correlation of these indicators with those of the other variables. It must be emphasized that because we treat 1,653 correlations, we only address the most significant ones for this study (*significant; ** very significant). The economic, educational and social variables for Brazil were correlated. 
BBR

15,6

595

Table 3. Economic indicators and control variables

\begin{tabular}{cc}
\hline Economic Indicators & Control Variable \\
\hline Gross Value of Industrial Production & $\mathrm{V} 1 \mathrm{C} 1$ \\
Consumption of cement & $\mathrm{V} 2 \mathrm{C} 1$ \\
Number of patent filings & $\mathrm{V} 3 \mathrm{C} 1$ \\
S\&T Expenditures & $\mathrm{V} 4 \mathrm{C} 1$ \\
Public Debt & $\mathrm{V} 5 \mathrm{C} 1$ \\
Unemployment rate & $\mathrm{V} 6 \mathrm{C} 1$ \\
Inflation index & $\mathrm{V} 7 \mathrm{C} 1$ \\
Balance of the Trade Balance & V8C1 \\
Trademark Application & V9C1 \\
Gross Domestic Product - GDP & V10C1 \\
Average household income per capita & V11C1 \\
Average income value & V12C1 \\
Employed Population & V13C1 \\
Number of deposits of computer programs & V14C1 \\
Rate of Economically Active Population & V15C1
\end{tabular}

Source: The authors (2016), based on public data.

Table 4. Educational indicators and control variables

\begin{tabular}{|c|c|}
\hline Educational Indicators & Control Variable \\
\hline $\begin{array}{c}\text { Youth rate - } 15 \text { to } 17 \text { years old enrolled - High } \\
\text { School }\end{array}$ & V1C2 \\
\hline Number of Higher Education Institutions & $\mathrm{V} 2 \mathrm{C} 2$ \\
\hline $\begin{array}{c}\text { Students who Completed higher education - Face- } \\
\text {-to-face }\end{array}$ & $\mathrm{V} 3 \mathrm{C} 2$ \\
\hline $\begin{array}{l}\text { Graduated in Doctor Degree by Federal Unit ( sta- } \\
\text { tes) and Brazil }\end{array}$ & $\mathrm{V} 4 \mathrm{C} 2$ \\
\hline Graduated in the Master Degree by FU and Brazil & $\mathrm{V} 5 \mathrm{C} 2$ \\
\hline $\begin{array}{c}\text { Number of Postgraduate Grants awarded by CA- } \\
\text { PES }\end{array}$ & V6C2 \\
\hline $\begin{array}{l}\text { Functional Illiteracy Rate of Population - } 15 \text { years } \\
\text { and over }\end{array}$ & V7C2 \\
\hline Rate of 15-17 year olds attending school & $\mathrm{V} 8 \mathrm{C} 2$ \\
\hline $\begin{array}{l}\text { Number of Graduate Programs (M/D) with concept } \\
5\end{array}$ & V9C2 \\
\hline Number of faculty in Higher Education & V10C2 \\
\hline Number of PhD Faculty in Higher Education & $\mathrm{V} 11 \mathrm{C} 2$ \\
\hline $\begin{array}{c}\text { Number of years of study - People aged } 25 \text { years } \\
\text { or more }\end{array}$ & $\mathrm{V} 12 \mathrm{C} 2$ \\
\hline $\begin{array}{l}\text { Number of years of School Lag - young people } \\
\text { from } 10 \text { to } 14 \text { years old }\end{array}$ & $\mathrm{V} 13 \mathrm{C} 2$ \\
\hline Illiteracy Rate, older than 10 years & $\mathrm{V} 14 \mathrm{C} 2$ \\
\hline Number of face-face Courses & $\mathrm{V} 15 \mathrm{C} 2$ \\
\hline
\end{tabular}

Source: The authors (2016), based on public data. 
Table 5. Social indicators and control variables

\begin{tabular}{cc}
\hline Social Indicators & Control Variable \\
\hline Population projection & $\mathrm{V} 1 \mathrm{C} 3$ \\
Gini Coefficient & $\mathrm{V} 2 \mathrm{C} 3$ \\
Number of jobs available & $\mathrm{V} 3 \mathrm{C} 3$ \\
Number of physicians per inhabitant & $\mathrm{V} 4 \mathrm{C} 3$ \\
Household rate with water supply & $\mathrm{V} 5 \mathrm{C} 3$ \\
Rate of Adequate Sanitary Sewage & $\mathrm{V} 6 \mathrm{C} 3$ \\
Employee formal contract rate & $\mathrm{V} 7 \mathrm{C} 3$ \\
Rate of Appropriate Garbage Collection & $\mathrm{V} 8 \mathrm{C} 3$ \\
Household Rate of Precarious Housing Situation & $\mathrm{V} 9 \mathrm{C} 3$ \\
Rate of Extreme Poverty & $\mathrm{V} 10 \mathrm{C} 3$ \\
Rate of Urban Lighting & $\mathrm{V} 11 \mathrm{C} 3$ \\
Rate of Urbanization & $\mathrm{V} 12 \mathrm{C} 3$ \\
Household Rate with all essential services & $\mathrm{V} 13 \mathrm{C} 3$ \\
Rate of Population Participation & $\mathrm{V} 14 \mathrm{C} 3$ \\
Theil Index (distribution inequality individuals $\mathrm{x}$ & $\mathrm{V} 15 \mathrm{C} 3$ \\
\hline Income &
\end{tabular}

Source: The authors (2016), based on public data.

Table 6. Economic indicators with the greatest variations regarding Brazil

\begin{tabular}{cccccccc}
\hline Year & (Mil/ton) & $($ Un $)$ & $(1.00 \mathrm{BRL})$ & $(1.00 \mathrm{BRL})$ & $(\mathrm{Un})$ & $(\mathrm{Un})$ & $(\%)$ \\
\hline & V2.C1 & V3.C1 & V6.C1 & V8.C1 & V9.C1 & V14.C1 & V15.C1 \\
\cline { 2 - 8 } 2001 & 38,912 & 21,555 & 10.00 & $2,641,924,000.00$ USD & 84,574 & 601 & 60.46 \\
2002 & 38,873 & 20,334 & 9.90 & $13,129,854,000.00$ USD & 80,712 & 693 & 61.31 \\
2003 & 34,884 & 20,176 & 10.50 & $24,824,547,000.00$ USD & 81,781 & 765 & 61.40 \\
2004 & 35,734 & 20,431 & 9.70 & $33,693,424,000.00$ USD & 80,071 & 766 & 62.02 \\
2005 & 37,666 & 21,852 & 10.20 & $44,756,852,000.00$ USD & 83,002 & 671 & 62.89 \\
2006 & 41,027 & 23,152 & 9.20 & $46,074,080,000.00$ USD & 77,547 & 665 & 62.42 \\
2007 & 45,062 & 24,840 & 8.90 & $40,028,195,000.00$ USD & 83,828 & 670 & 62.03 \\
2008 & 51,571 & 26,641 & 7.80 & $24,745,809,000.00$ USD & 99,363 & 818 & 61.97 \\
2009 & 51,892 & 25,885 & 9.00 & $25,347,409,000.00$ USD & 94,255 & 938 & 62.10 \\
2010 & 60,008 & 28,099 & 8.15 & 20.266 .610 .000 .00 USD & 103,988 & 1182 & 61.06 \\
2011 & 64,972 & 31,881 & 7.30 & $29,796,166,000.00$ & 122,458 & 1261 & 60.02 \\
2012 & 69,324 & 33,569 & 6.70 & $19,430,645,000.00$ USD & 120,431 & 1436 & 60.46 \\
2013 & 70,967 & 34,050 & 7.10 & $2,557,744,000.00$ USD & 132,330 & 1058 & 60.68 \\
\hline
\end{tabular}

Source: The authors (2016), based on primary data. 
BBR

15,6

597

Table 7. Educational indicators with the greatest variations regarding Brazil

\begin{tabular}{cccccccc}
\hline Year & $(\mathrm{Un})$ & $(\mathrm{Un})$ & $(\mathrm{Un})$ & $(\mathrm{Un})$ & $(\mathrm{Un})$ & $(\mathrm{Un})$ & $(\%)$ \\
\hline & V2.C2 & V4.C2 & V5.C2 & V9.C2 & V10.C2 & V13.C2 & V14.C2 \\
\cline { 2 - 8 } 2001 & 1,391 & 6,040 & 19,641 & 589 & 219,947 & 1.20 & 11.38 \\
2002 & 1,637 & 6,894 & 23,457 & 692 & 242,475 & 1.10 & 10.91 \\
2003 & 1,859 & 8,094 & 25,997 & 799 & 268,816 & 1.00 & 10.67 \\
2004 & 2,013 & 8,093 & 24,755 & 791 & 293,242 & 1.00 & 10.59 \\
2005 & 2,165 & 8,989 & 28,605 & 862 & 305,960 & 1.00 & 10.27 \\
2006 & 2,270 & 9,366 & 29,742 & 961 & 316,682 & 0.90 & 9.64 \\
2007 & 2,281 & 9,915 & 30,559 & 1.017 & 334,688 & 1.00 & 9.32 \\
2008 & 2,252 & 10,711 & 33,360 & 1.065 & 338,890 & 1.00 & 9.19 \\
2009 & 2,314 & 11,368 & 35,686 & 1.094 & 359,089 & 1.10 & 8.93 \\
2010 & 2,378 & 11,314 & 36,247 & 1.140 & 366,882 & 1.10 & 7.90 \\
2011 & 2,365 & 12,321 & 39,544 & 1.227 & 378,257 & 1.00 & 7.98 \\
2012 & 2,416 & 13,912 & 42,878 & 1.283 & 378,939 & 0.90 & 7.87 \\
2013 & 2,391 & 15,585 & 45,401 & 1.120 & 383,683 & 0.90 & 7.68
\end{tabular}

Source: The authors (2016), based on primary data.

Table 8. Social indicators with the greatest variations regarding Brazil

\begin{tabular}{ccccccccc}
\hline Year & $($ Un $)$ & $(\%)$ & $(\%)$ & $(\%)$ & $(\%)$ & $(\%)$ & $(\%)$ & $(\%)$ \\
\hline & V1.C3 & V6.C3 & V8.C3 & V9.C3 & V11.C3 & V12.C3 & V13.C3 & V14.C3 \\
\cline { 2 - 9 } 2001 & $172,385,826$ & 53.89 & 83.22 & 3.06 & 96.02 & 64.05 & 85.16 & 57.90 \\
2002 & $174,632,960$ & 62.06 & 84.81 & 2.68 & 96.65 & 65.51 & 85.56 & 58.60 \\
2003 & $176,871,437$ & 62.43 & 85.60 & 2.44 & 96.98 & 66.22 & 85.63 & 58.60 \\
2004 & $181,581,024$ & 62.17 & 84.65 & 2.80 & 96.77 & 65.86 & 84.37 & 59.20 \\
2005 & $184,184,264$ & 62.17 & 85.55 & 2.48 & 97.09 & 66.83 & 84.26 & 59.80 \\
2006 & $186,770,562$ & 62.76 & 86.38 & 2.34 & 97.59 & 67.79 & 84.45 & 59.30 \\
2007 & $183,554,226$ & 64.76 & 87.16 & 2.24 & 98.13 & 70.30 & 84.52 & 59.00 \\
2008 & $189,612,814$ & 64.60 & 87.69 & 1.98 & 98.53 & 70.39 & 84.61 & 59.00 \\
2009 & $191,506,729$ & 64.37 & 88.45 & 1.73 & 98.86 & 69.78 & 84.73 & 59.40 \\
2010 & $191,941,613$ & 66.07 & 88.54 & 1.83 & 99.01 & 71.86 & 86.14 & 58.45 \\
2011 & $192,376,496$ & 67.76 & 88.82 & 1.92 & 99.33 & 73.95 & 85.96 & 57.50 \\
2012 & $193,976,530$ & 68.65 & 88.79 & 1.37 & 99.52 & 74.26 & 85.76 & 57.50 \\
2013 & $201,062,789$ & 68.18 & 89.35 & 1.51 & 99.57 & 73.25 & 85.98 & 57.30
\end{tabular}

Source: The authors (2016), based on primary data.

\subsubsection{ANALYSIS OF THE ECONOMIC VARIABLE}

Regarding the economic variable (C1), there are 28 correlations. Half of these (14) are very significant $(* *)$, evidencing that these indicators can relate to one another by providing specific characteristics to the environment. Among the very significant correlations, 13 are directly related, that is, the increase in the value of an indicator implies an increase of a correlated one.

The indicator that most correlated with the others was the code "V2C1" - cement consumption, which was related to six other indicators in a significant way, followed by indicators "V1C1" - gross value of industrial production and "V3C1" - number of patent filings. These indicators characterize a particular type of environment depending on they appear positively or negatively. 
A very significant direct correlation was characterized in the pair "V1C1-V3C1" (Cc $0.711^{* *}$; pvalue 0.010 ), where it is necessary that the increase in the gross value of the national production is directly correlated to the number of patent filings. The converse is also true, since the reduction of one indicator will also produce the same effect, reducing the other correlated.

This reasoning applies to other correlated pairs. We must highlight the only very significant indirect correlation, synthesized in the pair "V2C1-V6C1" (Cc $-0.750 * *$; pvalue 0.005). The relationship between cement consumption and the unemployment rate was indirectly linked; the increase of one indicator reduces the other. Cement consumption is related to the acceleration of the economy, implying the demand for labor; the faster the economy, the greater the absorption of workers into employment opportunities, the lower the rate of unemployment.

Among the 28 pairs of correlated indicators a perfect correlation was identified, indicated by the pair "V2C1-V3C1" (Cc 0.949**; pvalue 0.000). By this relation, the consumption of cement is perfectly correlated with the number of patent filings. The statistics referring the values of these two indicators can be linked. The consumption of cement, related to the acceleration of the economy or the development of a certain location, is in some way linked to an environment conducive to development, reflecting the increase in the number of patent filings.

The indicators of the same variable, in this case the economic one, are related to each other, considering the 28 significant and very significant correlations, and that one exerts influence on the other, since most are positively related. Thus, a block of indicators of the same economic variable can provide a positive or negative environment, according to the performance correlated over the years; and reality supports this statistical evidence.

\subsubsection{ANALYSis OF THE EDUCATIONAL VARIABLE}

In examining data concerning hypothesis $\mathrm{H} 1$, considering only the indicators of the educational variable in Brazil, we observe the presence of 12 correlated pairs, 8 being significant $(*)$ and four very significant $(* *)$. We also found that seven of these correlations are direct and five indirect.

Among the very significant pairs, some relationships are elementary, as the correlation of pairs "V2C2-V10C2" (Cc 0.720**; pvalue 0.008) and "V2C2-V15C2" (Cc 0.713**; pvalue 0.009), which emphasizes the validity and reliability of the statistical calculation, since the higher the number of Higher Education Institutions, the higher the number of faculty in higher education and the greater the number of face-to-face courses, which is the most common modality.

An important indirect correlation is represented by the pair "V7C2-V9C2" $(\mathrm{Cc}-0.720$ **; pvalue 0.008), indicating the existence of a close relationship between the reduction of the functional illiteracy rate of the population aged 15 years or older and the search for a better level of study, because the lower the illiteracy rate, the greater the number of graduate programs, in master's and doctoral level with concept " 5 ".

Amongst the educational indicators that most correlate with each other are the "V2C2" - number of higher education institutions, and the "V3C2" - graduates in higher education (face-to-face). The indicators that most correlate with economic indicators are "V2C2" and the "V15C2" - number of face-to-face institutions and courses. The loadings of significance of these correlations show that the link between the economic and educational environments are evidenced and conform a specific environment.

In analyzing the most significant correlated pairs and those that are directly related, the reflection of one over the other is large, which gives a distinct characteristic to the environment depending on how the indicators of this variable are presented. 
BBR

15,6

\subsubsection{ANALYSIS OF THE SOCIAL VARIABLE}

In relation to social variables, there are 11 correlations between its indicators, highlighting that seven are significant and four are very significant, and among these, only one is very significant and indirectly correlated.

There is a direct and very significant relationship between the pair of indicators "V2C3V15C3" (Cc 0.764**; pvalue 0.004), indicating that the Gini index or coefficient, which refers to the measure of social inequality of a country or region, characterizing income concentration, is directly related to the Theil index, which measures the inequality in the distribution of individuals according to per capita household income.

Another very significant correlation adheres to the pair "V6C3-V7C3" (Cc 0.817**; pvalue 0.001 ), the rate of adequate sanitary sewage and employee formal contract rate are directly related. This fact refers to the more structured environment, where the formally contracted worker is more able to perceive the importance of adequate sanitary sewage to the health of their family. These two associated indicators denote a more conscious and developed environment in terms of quality of life.

To characterize the formation of a specific social environment, the pair correlation "V13C3-V14C3" (Cc-0.852**; pvalue 0.000), shows that more urbanized areas denote, lower rate of population participation, defined by the number of people who work at least one full hour in paid work. This means that in an urbanized place it is common to have better living conditions, smaller families and, especially, the younger devote themselves to studies. In less urbanized areas, it is normal for larger families and under less favored conditions, leading the younger ones to seek work to help support the family.

\subsubsection{CONSIDERATIONS ON INDICATORS AND CORRELATIONS}

In the intra and intercorrelations of indicators of economic, educational and social variables there are perfect correlations (pvalue $=0.000$ ) in the pairs "V2C1-V3C1", "V11C1V15C2", "V15C1-V14C3" and "V13C3-V14C3", as well as in the number of pairs with correlation coefficients $(\mathrm{Cc})$ above 0.800 , with pvalue close to zero.

The various indicators related to the researched variables assume different values over a period of time, varying between positive and negative positions, as can be observed in the values of Tables 6,7 and 8 .

By analyzing the values and correlations of the indicators of the studied variables, the hypothesis $\mathrm{H} 1$ is confirmed as a result of the consolidation of differentiated formats of the environments resulting from the interaction of these indicators and variables. Therefore, it is proved that variables can assume different positions over time and that effectively correlate with one another, providing the environment with unique and specific configurations. Thus, hypothesis $\mathrm{H} 1$ is true.

\subsection{Research Hypothesis TeSt - H2}

To test the second hypothesis we adopt a basic premise. The economic, educational and social variables may present indicators with positive or negative characteristics, that is, the indicators of each variable grouped can express how they appear in the environment. As an example, the economic environmental variable (VAEc) may be positive, characterized by its pooled indicators, reflecting a development environment, or negative, implying a recessionary environment. The environmental educational variable (VAEd) may change from an evolved situation to the obsolete one; and the social environmental variable (VASo), may range from an advanced to a stagnant environment. 
In this research the political environmental variable was disregarded, as explained in the methodology. Thus, the environmental configuration approach (CA) in this study admitted two extreme possibilities for each variable, one positive and one negative, with eight Environmental Configurations $(\mathrm{CA}=>23=8)$, ranging from an extremely positive configuration $(+++)$ to the other extremely negative (---). These possibilities are characterized in Table 9.

The correlations referring to Brazil has 143 correlated pairs presenting significance, with 66 being very significant and 77 significant. In order to test whether hypothesis $\mathrm{H} 2$ is true or not, the intercorrelation between the indicators of the several environmental variables of São Paulo, Paraná and Sergipe were verified.

Initially, we analyzed São Paulo, considered for the purpose of this study as the most developed and innovative state. It should be noted that the variables and indicators are the same as those considered for Brazil. What differs are the values of each indicator, obtained from primary sources. The first finding refers to the number of correlations. While in Brazil the number was 143 , with $46 \%$ of correlations being very significant, in São Paulo it totaled 117 , with only $32 \%$ being very significant, characterizing a more homogeneous environment.

The distributions of the correlations are not the same, including changes occurring in the distribution of pairs of indicators with more significant correlations, as well as the correlation coefficients in São Paulo are stronger, that is, they have greater loading. Considering that the São Paulo environment is more stable in relation to Brazil, it is justified that correlations, especially with respect to economic indicators, have greater loadings. The balance between environmental variables provides stability to the indicators.

Effectively, the indicators make the São Paulo environment a differentiated place in ter$\mathrm{ms}$ of positive correlation of the various indicators of environmental variables. Correlation Coefficients, such as pairs "V2C1-V4C1" $\left(\mathrm{Cc}=0.853^{* *}\right.$ and pvalue $\left.=0.000\right)$ and "V2C1$\mathrm{V} 8 \mathrm{C} 1 "\left(\mathrm{Cc}=0.855^{* *}\right.$ and pvalue $\left.=0.000\right)$, indicating perfect correlations, show that the indicators are intrinsically associated.

The values that corroborate for this assertion are mainly the indicators of the educational variable, which are consistent in terms of correlation. There are positive values when compared to Brazil. The correlation coefficients confirm the consistency of the environment, because there are perfect correlations for educational indicators such as in pairs "V2C2V7C3" $(\mathrm{Cc}=-0.849 * *$ and pvalue $=0.000)$ and "V13C2-V8C1" $(\mathrm{Cc}=-0.870 * *$ and pvalue $=0.000)$, in addition to several strong correlations, with correlation coefficients close to 1 (absolute value), very significant and with pvalue close to zero, as is the case of pairs

Table 9. Possibilities of Environmental Configurations

\begin{tabular}{|c|c|c|c|c|c|c|}
\hline \multirow{3}{*}{ Configuration } & \multicolumn{6}{|c|}{ Environmental Macro variables } \\
\hline & \multicolumn{2}{|c|}{ Economic - VAEc } & \multicolumn{2}{|c|}{ Educational - VAEd } & \multicolumn{2}{|c|}{ Social - VASo } \\
\hline & Positive & Negative & Positive & Negative & Positive & Negative \\
\hline CA1 & $\mathrm{x}$ & & $\mathrm{x}$ & & $\mathrm{x}$ & \\
\hline CA2 & $\mathrm{x}$ & & $\mathrm{X}$ & & & $\mathrm{x}$ \\
\hline CA3 & $\mathrm{X}$ & & & $\mathrm{x}$ & $\mathrm{x}$ & \\
\hline CA4 & $\mathrm{x}$ & & & $\mathrm{x}$ & & $\mathrm{x}$ \\
\hline CA5 & & $\mathrm{x}$ & $\mathrm{x}$ & & $\mathrm{X}$ & \\
\hline CA6 & & $\mathrm{x}$ & $\mathrm{x}$ & & & $\mathrm{x}$ \\
\hline CA7 & & $\mathrm{x}$ & & $\mathrm{x}$ & $\mathrm{x}$ & \\
\hline CA8 & & $\mathrm{x}$ & & $\mathrm{x}$ & & $\mathrm{x}$ \\
\hline
\end{tabular}

Source: The authors (2016). 
BBR

15,6

601

"V2C2-V9C1" $(\mathrm{Cc}=-0.827 * *$ and pvalue $=0.001)$ and "V3C2-V15C2" $(\mathrm{Cc}=-0.839 * *$ and pvalue $=0.001)$.

The main data of the state of Paraná, considered median in terms of development in the criteria of this study is presented to broaden the analyzes and considerations about the relationships of the indicators in the several variables. The comparison of the correlations in Brazil and São Paulo with those of Paraná shows that the environments are effectively different considering the coefficient of correlation of the economic, educational and social indicators.

The data for Paraná are distinct in relation to Brazil and São Paulo, mainly due to the fact that only $22 \%$ of the total correlations are very significant, against $46 \%$ of Brazil and $32 \%$ of São Paulo. This factor reinforces the argument of the divergence of environmental configurations considering the values of the indicators.

The pairs characterized as very significant have Correlation Coefficients below 0.800, as the cases of pairs "V4C1-V9C1" $\left(\mathrm{Cc}=-0.713^{* *}\right.$ and pvalue $\left.=0.009\right)$; "V8C1-V15C1" $\left(\mathrm{Cc}=-0.795^{* *}\right.$ and pvalue $\left.=0.001\right)$; "V8C1-V6C2" $(\mathrm{Cc}=-0.727 * *$ and pvalue $=0.007)$; "V10C1-V11C1" $\left(\mathrm{Cc}=0.734^{* *}\right.$ and pvalue $\left.=0.007\right)$; and "V11C1-V3C2" $\left(\mathrm{Cc}=-0.713^{* *}\right.$ and pvalue $=0.009$ ), among others, denoting reduction of the correlation loading, which characterizes this environment as inferior if considered to that of São Paulo.

The crisis that affected several environments between 2008 and 2009 was not reflected, at least not immediately, in the various social indicators of the State of Paraná. During this period most of the indicators improved, especially the increase of the number of available jobs "V3C3" and rate of urbanization "V13C3", as well as reducing the rate of extreme poverty "V10C3", which declined even in adverse conditions.

To consolidate the diagnosis, aiming to confirm or not hypothesis $\mathrm{H} 2$, we inserted the data of the environmental variables of Sergipe. This environment is considered themost modest variables for the purpose of this study, as a stagnant environment. The term "stagnant" refers specifically to a condition that serves the purposes of this study.

Sergipe presents 113 correlated environmental indicators. Despite the modest indicators, the number of very significant correlations was high, with $30 \%$ of the total, denoting that there is a specific effort to change the environment. Among those surveyed, this state is the one that presents the most perfect correlations, with a high coefficient of correlation $(\mathrm{Cc})$ and pvalue equal to zero. Among these, "V4C1-V11C1" $(\mathrm{Cc}=0.881 * *$ and pvalue $=0.000$ ), correlating expenditures on $\mathrm{S} \& \mathrm{~T}$ and the number of $\mathrm{PhD}$ faculty in higher education. This relationship is perfectly plausible, since the greater number of physicians in higher education implies more research, with the necessary investment in physical and technological resources.

However, attention is drawn to the pair "V8C1-V14C1" $\left(\mathrm{Cc}=-0.893^{* *}\right.$ and pvalue $=$ 0.000 ), which inversely correlates the balance of trade and the number of deposits of computer programs. It seems to be an inconsistency a better balance in the trade balance entail a reduction of the creation of computer programs. However, this is a feature of a stagnant environment. This is reinforced by the pair "V8C1-V7C3" $(\mathrm{Cc}=0.879 * *$ and pvalue $=$ 0.000 ), which presents a perfect indirect correlation between the trade balance and number formally contracted workers. We can perceive another contradiction, since there is a direct relationship between these two indicators, since the better the trade balance, more positive economic conditions, reflected in the number of employment and the employee formal contract rate. 
Although certain findings seem illogical, this fact implies in the specificity of the state of Sergipe, which characterizes the differentiations of indicators and variables, as well as how they correlate and form a specific context.

The indicators of the environmental variables of Sergipe were the most affected in the crisis of 2008-2009, considering some negative results or slight increases in certain indicators. There was a sharp reflection in the employment rate (V7C1) and successive deficits in the balance of the trade balance $(\mathrm{V} 8 \mathrm{C} 1)$ throughout the series, despite the increase in the value of GDP (V10-C1). This fact, once again must be evidenced, because it indicates that the studied sites have specificities depending on the set of correlations between their indicators and variables.

Not unlike the indicators of the economic variable, the educational and social indicators of Sergipe also show marked diversity in relation to classified sites as developed and medium. The modest indexes regarding the educational variable must be highlighted. Some indicators practically do not exist when compared to São Paulo and Paraná, as the number of graduates in the doctor degree "V4C2". The official statistic indicates that in the years 2001-2003 there were no persons qualified in this degree. Until 2009, Sergipe had only 10 PhDs.

There is actually a difference between the places surveyed. After present, discuss and characterize the three places in this study, it we can be said that correlated indicators provide specific characteristics for each environmental variable. And the interrelated environmental variables form a particular context reflects the specificities of the indicators captured for this reality.

Analyzing the results and considering the intra and intercorrelations of the indicators of the economic, educational and social variables, the sites studied can be classified in relation to the Environmental Configurations in Table 10. Thus, with the correlation data of the three states under analysis, São Paulo presents the most significant correlations considering the economic, educational and social aspects. The difference in the values of the indicators in relation to the other analyzed states is notable, providing an advantageous conjuncture for development in this state, as there are the necessary resources in quantity and quality.

The state of Paraná presents economically, values that do not leave a great deal to be desired. However, in terms of educational resources, although not so bad, the state has a lot of room to develop.

Finally, the state of Sergipe is far from desired when compared to the other two states. Despite efforts to develop, which are reflected in recent public data on this state, the reality is still far from the ideal. The indicators of economic, educational and social variables allow asserting that Sergipe lacks the resources to be able to leverage the bases for innovation and consequent competitiveness. And because it does not gather in quantity and quality such resources, the state can be classified, for the purposes of this study, as stagnant.

Therefore, considering the possibilities of environmental configurations and the characteristics of the studied states, we can classify these as follows: São Paulo: CA1; Paraná: CA3; and Sergipe: CA8, according to Table 10.

Thus, despite the fact that only three specific environments were characterized, the second hypothesis of the research, was confirmed. It can effectively result in the eight environmental configurations, with the surveyed sites being classified according to these configurations. Therefore, hypothesis $\mathrm{H} 2$ is true. 
BBR

15,6

603

Table 10. Classification of Environmental Configurations of the researched places

\begin{tabular}{|c|c|c|c|c|c|c|c|}
\hline \multirow{2}{*}{\multicolumn{2}{|c|}{ Configuration }} & \multicolumn{6}{|c|}{ Environmental variables } \\
\hline & & \multicolumn{2}{|c|}{ Economic - VAEc } & \multicolumn{2}{|c|}{ Educational - VAEd } & \multicolumn{2}{|c|}{ Social - VASo } \\
\hline & & Positive & Negative & Positive & Negative & Positive & Negative \\
\hline \multirow[t]{2}{*}{ São Paulo } & CA1 & $\mathrm{x}$ & & $\mathrm{x}$ & & $\mathrm{x}$ & \\
\hline & CA2 & & & & & & \\
\hline \multirow[t]{5}{*}{ Paraná } & CA3 & $\mathrm{x}$ & & & $\mathrm{x}$ & $\mathrm{x}$ & \\
\hline & CA4 & & & & & & \\
\hline & CA5 & & & & & & \\
\hline & CA6 & & & & & & \\
\hline & CA7 & & & & & & \\
\hline Sergipe & CA8 & & $\mathrm{x}$ & & $\mathrm{x}$ & & $\mathrm{x}$ \\
\hline
\end{tabular}

Source: The authors (2016).

\section{Final Considerations}

Effectively the environmental characteristics present reflexes in the level of innovation and development in relation to the place in which it is analyzed, according to Damanpour (1996); Tidd (2001); Oslo Manual (2005); Zhang, Majid and Foo (2011) and Tsuja and Mariño (2013).

The study sought to demonstrate that environmental variables can assume differentiated values over a given period and associate themselves to form different environmental configurations. Thus, if the possible configurations of the environment are characterized, it is feasible to identify which indicators are most adequate to measure innovation, thus meeting the basic condition for managing innovation: measure to manage with competitiveness in sight.

After we established the two hypotheses of research, we verified that the environmental variables - economic, educational and social - assume different values over a certain period of time, ranging from positive to negative, as well as correlate with one another. It is also found that the correlations of these variables, in their different forms (positive or negative), eight different environmental configurations may result.

Therefore, it is evidenced that a new need arises in the study of innovation measurement, which is to characterize and identify in what environmental context the innovation process occurs so that it is possible to select which indicators are the most adequate for achieving this purpose. However, in order to make this attempt feasible, studies are needed that relate the indicators of innovation measurement to the respective environmental configurations.

Therefore, it is mandatory to conduct new studies to expand the scope of approach to the theme, since in this research the environmental policy variable was not considered due to the absence of valid and reliable indicators for its treatment.

Thus, failure to consider the political variable is a limitation of this study, because, in theory, there is the possibility of conformation of 16 environment configurations $(\mathrm{CA}=>24$ $=16$ ), and this study considers only the economic, educational and social variables, totaling eight possible environmental configurations.

Finally, the knowledge of the possible environmental configurations allows understanding the interaction between the environment and innovation. It allows greater rationality to the innovative process, because the activity of measuring innovation according to the 
type of context where it occurs makes management more effective with the ensuing desired results, such as competitiveness.

\section{REFERENCES}

BARNEY, J. B. Firm resources and sustained competitive advantage. Journal of Management, v. 17, n. 1, 1991.

BERTALANFFY, L. V. General Systems Theory: foundations, development, application. New York: George Braziller, 1968.

BHATTACHERJEE, A. Social Science Research: principles, methods, and practices. Textbooks collection, book 3. Tampa: University of South Florida, 2012.

CASSIOLATO, J. E.; LASTRES, H. M. M. Local systems of innovation in the Mercosur facing the challenge of the 1990's. Industry and Innovation, v. 7, n. 1, pp. 34-51, 2000.

DAMANPOUR, F. Organizational complexity and innovation: developing and testing multiple contingency models. Management Science, v. 42, n. 5, p. 693-716, 1996.

DUNCAN, R. Characteristics of organizational environments and perceived environmental uncertainty. Administrative Science Quarterly, v. 17, n. 3, pp. 313-327, 1972.

EXAME. Estes são os 11 estados mais competitivos do Brasil. Revista Exame.com, São Paulo, 2015, novembro. Disponível em: <http://exame.abril.com.br/economia/noticias/estes-sao-os-11-estados-maiscompetitivos-do-brasil\#10>.

FREEMAN, C.; SOETE, L. Developing science, technology e innovation indicator: what we can learn from the past. Work Paper Series, 2007-01, Maastricht, United Nations University, jan-2007.

GRETL - Gnu Regression, Econometric and Time-series Library - GRETL, 2013. Disponível em: < https:// sourceforge.net/projects/gretl/files/gretl/1.9.12/>. Acesso em: out. 2016.

HAMBRICK, D. C. Environmental scanning and organizational strategy. Strategic Management Journal, v. 13, n. 2, pp. 44-49, 1982.

IBM/SPSS. IBM Corp. Released. IBM SPSS Statistics for Windows, Version 21.0. Armonk, NY: IBM Corp., 2012.

LEVINE, D. M.; STEPHAN, D. F.; KREHBIEL, T. C.; BERENSON, M. L. Estatística - teoria e aplicações: usando o Microsoft Excel em português. 6 ed. Rio de Janeiro: LTC, 2015.

LI, H.; ATUAHENE-GIMA, K. Product innovation strategy and the performance of new technology ventures in China. Academy of Management Journal, New York, v. 44, n. 6, pp. 1123-1134, 2001.

MANKIW, N. G. Principles of macroeconomics. 3rd. ed. South-Western College, 2003.

McGEE, J. E.; SAWYERR, O. O. Uncertainty and Information Search Activities: A study of Owner-Managers of Small High-Technology Manufacturing Firms. Journal of Small Business Management, 41, n.4, pp. 385-401, 2003.

MOYSÉS FILHO, J.; KESTELMAN, H. N.; BEECKER Jr., L. C.; TORRES, M. C. S. Planejamento e gestão estratégica em organizações de saúde. Rio de Janeiro: Editora FGV, 2010.

MYBURGH, S. Competitive Intelligence: Bridging Organizational Boundaries. Information Management Journal, v. 38, n. 2, pp. 46-55, 2004.

OSLO manual: Guidelines for collecting and interpreting innovation: The measurement of scientific and technological activities data. 3rd. ed. Paris: Organisation for Economic Co-Operation and Development OECD: Luxembourg: Statistical Office of the European Communities - Eurostat, 2005. 163 p. Disponível em: <http://www.oecd-ilibrary.org/science-and-technology/oslo-manual_9789264013100-en>. Acesso em: nov. 2014.

PORTER, M. E. The five competitive forces that shape strategy. Harvard Business Review, 86, n. 1, jan., 2008.

RIBEIRO, G.; CHEROBIM, A. P. M. Z. Environment and innovation: discrepancy between theory and research practice. RAI Revista de Administração e inovação, v. 14, n. 1, pp. 30-40, jan-mar 2017a.

Configuração ambiental: a lacuna entre teoria e prática nos estudos de inovação. Revista Espacios, 2017, v. 38(12), mar. 2017 b. 
SANTOS, J. G. C. dos; VASCONCELOS, A. C. de; DE LUCA, M. M. M. Perfil da inovação e da internacionalização de empresas transnacionais. Revista de Administração e Inovação, São Paulo, v. 10, n.1, p. 198-211, Jan/Mar, 2013.

SCHUMPETER, J. The Theory of economic development. Harvard University Press, 1939.

SILVA, M. F. De O. e; DA SILVA, J. F.; MOTTA, L. F. J. da. A vantagem competitiva das nações e a vantagem competitiva da empresa: o que importa na localização. Revista de Administração Pública, Rio de Janeiro, 46 (3), pp. 701-720, mai./jun., 2012.

STEVENSON, W. J. Estatística Aplicada à Administração. São Paulo: Harper \& Row do Brasil, 1981.

TIDD, J. Innovation management in context: environment, organization and performance. International Journal of Management Reviews, v.3, n. 3, pp. 169-183, sep-2001.

TSUJA, P. Y.; MARINÕ, J. O. The influence of the government on organizational innovation in service companies in Peru. Review of Business Management, v. 15, n. 49, pp. 582-600, dez-2013.

ZHANG, X.; MAJID, S.; FOO, S. The contribution of environmental scanning to organizational performance. Singapore Journal of Library \& Information Management, v. 1, pp. 65-88, 2011. 